\title{
RESIDUAL STRESSES AND STRESS CORROSION CRACKING IN PIPE FITTINGS
}

\author{
Ronald J. Parrington \\ James J. Scatt \\ Freddie Torres
}

KAPL-4798

June 1994

Prepared for

The United States Department of Energy

Prepared by

Knolls Atomic Power Laboratory

P. O. Box 1072

Schenectady, New York 


\section{DISCLAIMER}

This report was prepared as an account of work sponsored by an agency of the United States Government. Neither the United States Government nor any agency' thereof, nor any of their employees, makes any warranty, express or implied, or assumes any legal liability or responsibility for the accuracy, completeness, or usefulness of any information, apparatus, product, or process disclosed, or represents that its use would not infringe privately owned rights. Reference herein to any specific commercial product, process, or service by trade name, trademark, manufacturer, or otherwise, does not necessarily constitute or imply its endorsement, recommendation, or favoring by the United States Government or any agency thereof. The views and opinions of authors expressed herein do not necessarily state or reflect those of the United States Government of any agency thereof. 


\section{DISCLAIMER}

Portions of this document may be illegible in electronic image products. Images are produced from the best available original document. 
Introduction........................................................................ 2

Experimental Procedures...................................................... 2

Test Results........................................................................

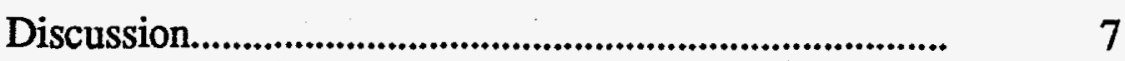

Conclusions.....................................................................

References..................................................................... 8

Acknowledgement............................................................... 8

Figures

Denhard Curve of Stress Level as a Function of Fracture Time.

Strain Gauge Locations.

Geometry Influence on Crack Initiation Time in 400C

Steam

Cracking Extent as a Function of Exposure Time in 400C Steam

Fabricator A - Alloy 600 Elbow Axial Residual Stresses (intrados).

Fabricator E - Alloy 600 Elbow Axial Residual Stresses (intrados).

Tables 


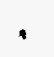

$\checkmark$ 


\title{
RESIDUAL STRESSES AND STRESS CORROSION CRACKING IN PIPE FITTINGS
}

\author{
Ronald J. Parrington \\ James J. Scott \\ Freddie Torres
}

Residual stresses in as-fabricated pipe fittings are sufficient to induce stress corrosion cracking (SCC) in susceptible materials exposed to $400^{\circ} \mathrm{C}$ steam environments. This has been demonstrated qualitatively for Alloy 600 fittings by testing in high purity $400^{\circ} \mathrm{C}$ steam and for stainless steel fittings by testing in boiling magnesium chloride. Quantitative residual stress measurements were performed on Alloy 600 elbows using the section and layer removal technique (SLR). Fittirgs manufactured from several fabricators were evaluated. Significant differences were observed suggesting that vendor manufacturing methods can significantly influence SCC susceptikility of fittings.

Fourteen Alloy 600 elbows from four different fabricators were tested in $400^{\circ} \mathrm{C}$ steam with $0.07 \mathrm{MPa}$ hydrogen. SCC on the inside surfaces was observed in as early as 6 weeks. Only fittings made by one fabricator have cracked. The time for SCC initiation decreases with decreasing fitting diameter and increasing wall thickness.

Thirty-six Type 304 stainless steel elbows from four different fabricators were tested in boiling magnesium chloride. The results suggest strong fabricator-to-fabricator differences in residual stresses. Specific cracking patterns can be attributed to bending, ball sizing and the use of expandable tapered plugs. A fabricatur ranking based on testing stainless steel fittings in magnesium chloride is consistent with the ranking obtained from testing Alloy 600 fittings in $400^{\circ} \mathrm{C}$ steam.

Two $7.6 \mathrm{~cm}$ schedule 160 Alloy 600 elbows from tiwe fabricators were destructively evaluated for residual stress using the SLR technique in which the fittings are strain-gauged and then sectioned, followed by layer removal. Stresses relieved at each step are recorded by the strain gauges and used to analyze the residual stresses. Stresses as high as $620 \mathrm{MPa}$ were measured and, consistent with $400^{\circ} \mathrm{C}$ steam and boiling magnesium chloride testing, as-fabricated stresses were twice as high in one fabricator's elbow. 


\section{INTRODUCTION}

Residual stresses can play a key role in the SCC performance of susceptible materials in PWR primary water applications. Residual stresses are stresses stored within the metal that develop during deformation and persist in the absence of external forces or temperature gradients. Sources of residual stresses in pipe fittings include fabrication processes, installation and welding.

There are a number of methods to characterize the magnitude and orientation of residual stresses. These include numerical analysis, chemical cracking tests, and measurement (e.g., X-ray diffraction, neutron diffraction, strain gage/hole drilling, strain gage/trepanning, strain gage/section and layer removal, and acoustics).

This paper presents $400^{\circ} \mathrm{C}$ steam SCC test results demonstrating that residual stresses in as-fabricated Alloy 600 pipe fittings are sufficient to induce SCC. Residual stresses present in as-fabricated pipe fittings are characterized by chemical cracking tests (stainless steel fittings tested in boiling magnesium chloride solution) and by the sectioning and layer removal (SLR) technique.

\section{EXPERIMENTAL PROCEDURE}

\section{$400^{\circ} \mathrm{C}$ Steam Test}

Fourteen Alloy 600 elbows from four different fabricators were tested in $400^{\circ} \mathrm{C}$ steam. Testing in this environment is believed to provide accelerated SCC data for nickel base alloys applicable to PWR primary water environments. The test specimen matrix is shown in Table 1. With the exception of elbows A-10w and A-12w, which were welded to short pipe segments at both ends, all elbows were tested in the asfabricated, unloaded condition.

$400^{\circ} \mathrm{C}$ steam testing was performed in a 60 -liter autoclave with system modifications to permit hydrogen and $\mathrm{pH}$ control. Monitoring and

control of hydrogen were achieved through a single Ag/ Pd transfer tube penetrating the autoclave head. The desired hydrogen concentration $(0.07+/-$ $0.01 \mathrm{MPa}$ )

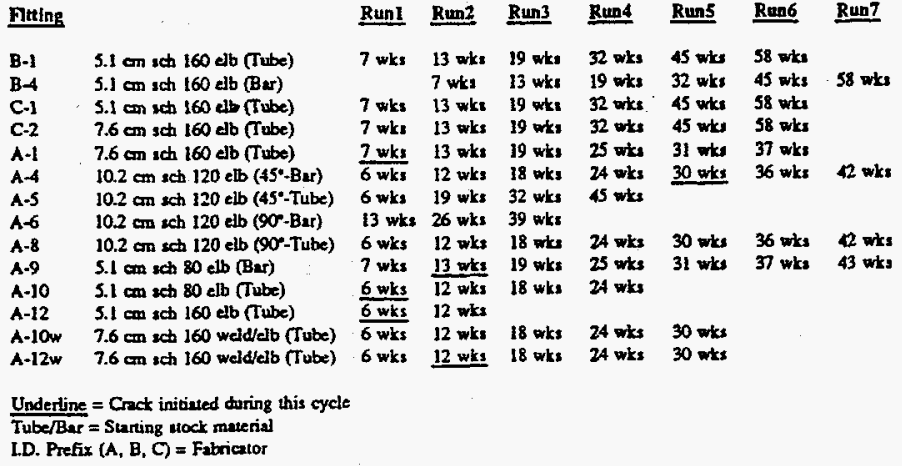

TABLE 1 - Alloy 600 Llbows in $400^{\circ}$ C Steam autoclave Testing 
was established with a hydrogen-argon mixed gas. A system pressure of $19.3+/-0.3 \mathrm{MPa}$ was maintained. The test facility was designed to permit the addition of makeup water at high temperature and pressure. Proper water chemistry was achieved by degassing the initial steam test environment to a low pressure $(\sim 0.7 \mathrm{MPa})$ and then adding high purity water ( $\mathrm{pH}$ of 10.0 to 10.3 , oxygen less than $10 \mathrm{ppb}$, and resistivity of 0.012 to $0.058 \mathrm{meg} \mathrm{ohm}-\mathrm{cm}$ ) until the desired system pressure is reached. Test temperature was controlled at $400^{\circ} \mathrm{C}+3 /-6^{\circ} \mathrm{C}$.

Pipe fittings tested in $400^{\circ} \mathrm{C}$ steam were removed from test periodically and inspected visually and ultrasonically for crack indications. Upon test completion, nondestructive inspection of pipe fittings was followed by destructive, metallographic examination. Only one elbow (A-1) has been terminated and destructively evaluated, to date.

\section{Boiling Magnesium Chloride Test}

Thirty-six Type 304 stainless steel elbows from four different fabricators were tested in boiling magnesium chloride solution. Boiling magnesium chloride induces cracking in stainless steel under tensile stress and was employed as a chemical cracking test to characterize residual stresses. The location and orientation of tensile residual stresses are revealed by the location and orientation of chloride induced cracking. A semi-quantitative estimate of the magnitude of residual stresses can be made based on the Reference (1) correlation of tensile stress magnitude to time to crack initiation (Figure 1). The test specimen matrix is shown in Table 2.

Testing was performed in accordance with ASTM G36 - "Standard Practice for Performing Stress-Corrosion Cracking Tests in a Boiling Magnesium Chloride Solution". The bench top test setup consisted of a large glass vessel equipped with a heating jacket, reflux column and an alarm for out-of-specification thermal excursions.

Pipe fittings were tested in boiling magnesium chloride for times ranging from 0.5 to 22 hours. Following test exposure, the pipe fittings were sectioned longitudinally and fluorescent penetrant inspected. Metallographic examination was also performed in

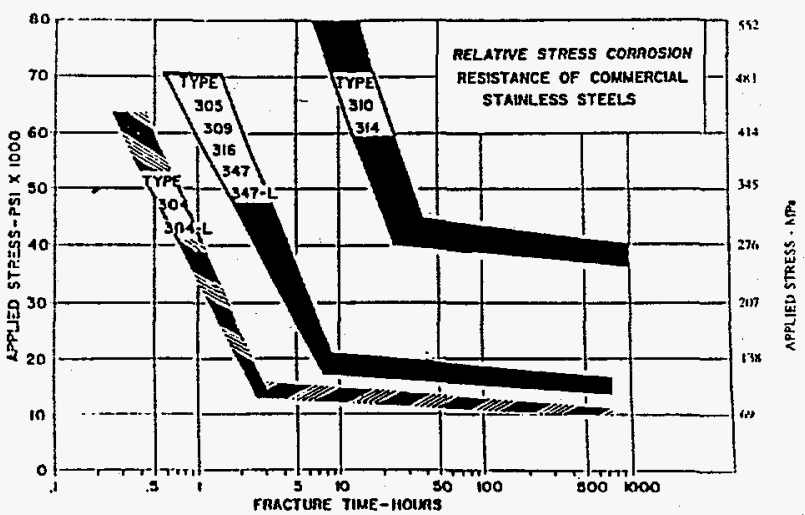

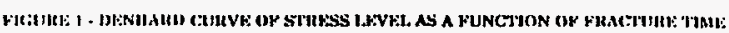
some instances. 


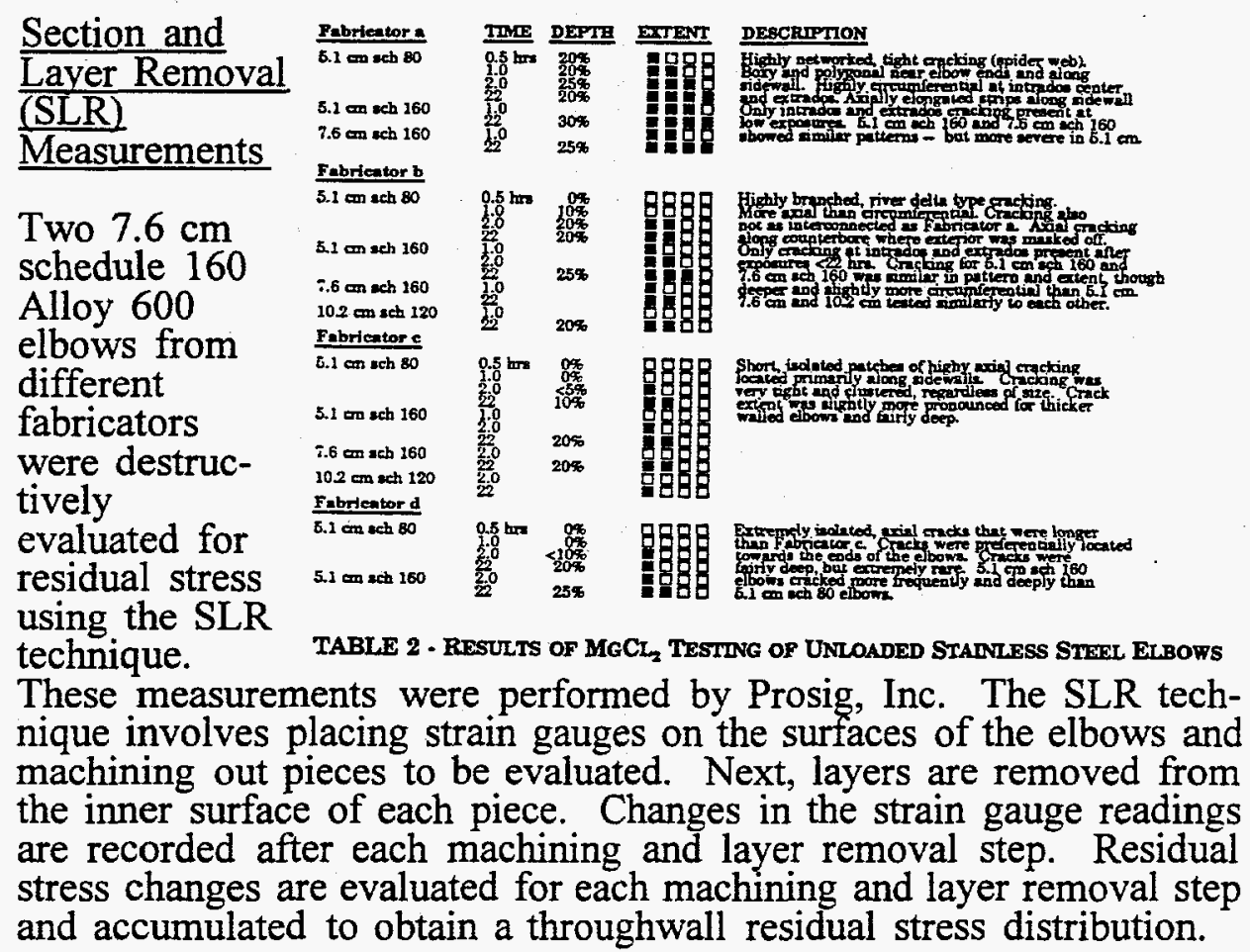

Twenty-four $90^{\circ}$ biaxial strain gauge rosettes were mounted on each elbow, 12 on the interior surface and 12 on the exterior surface. The two axes of the strain gauges were aligned with the axial and hoop directions of the elbows. The locations of the strain gauges are portrayed in Figure 2.

After initial strain readings were recorded, the elbows were cut into twelve pieces (Figure 2), each piece containing strain gauges on the inner and outer surface. Strain changes during sectioning were recorded. Next, the pieces were trimmed to. nominal dimensions of 3.22 $\mathrm{cm}$ wide (hoop direction) and $3.05 \mathrm{~cm}$ long. Strain changes due to trimming were
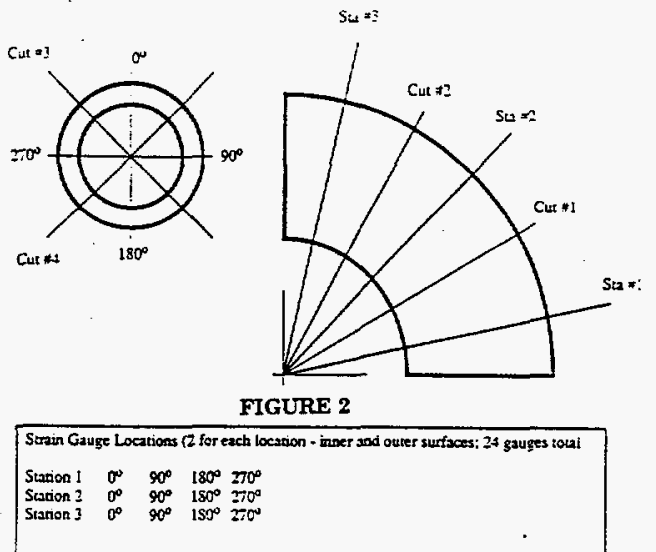
recorded. The final machining step involved removing layers from the inner surface of each piece to obtain data points at 0 (inner surface), 9 , $25,38,50,75$ and $100 \%$ throughwall thickness locations. Strain changes were recorded for each removed layer.

The residual stresses present in the as-fabricated elbows prior to any sectioning were computed from the recorded strain changes.

\section{TEST RESULTS}

\section{$400^{\circ} \mathrm{C}$ Steam Test}

Table 1 presents the $400^{\circ} \mathrm{C}$ steam SCC test results. To date, only elbows made by one of the four fabricators have cracked. No elbows made by the other three fabricators have cracked after test exposures up to 58 weeks.

SCC in Fabricator "a" elbows was observed in as early as 6 weeks. Cracking on all elbows was located primarily on the intrados of the elbow and ran circumferentially within $0-15^{\circ}$ off axis. Furthermore, with the exception of the cracked $10.2 \mathrm{~cm}$ schedule 120 elbow, all cracks propagated during subsequent test exposures. Destructive evaluation has revealed the cracking to be intergranular. The circumferential extent and depth of cracking was significant. Elbow A1 exhibited cracking that extended $360^{\circ}$ and up to $90 \%$ throughwall depth.

For data plotting purposes, independent cracks on the same elbow are plotted as unique points. Figure 3 shows a clear correlation of crack initiation time to the wall thickness-todiameter ratio. The thicker the wall and the smaller the diameter, the shorter the crack initiation time. Also, thicker walled and smaller diameter elbows generally propagate cracks deeper and more extensively through the elbows (Figure 4).

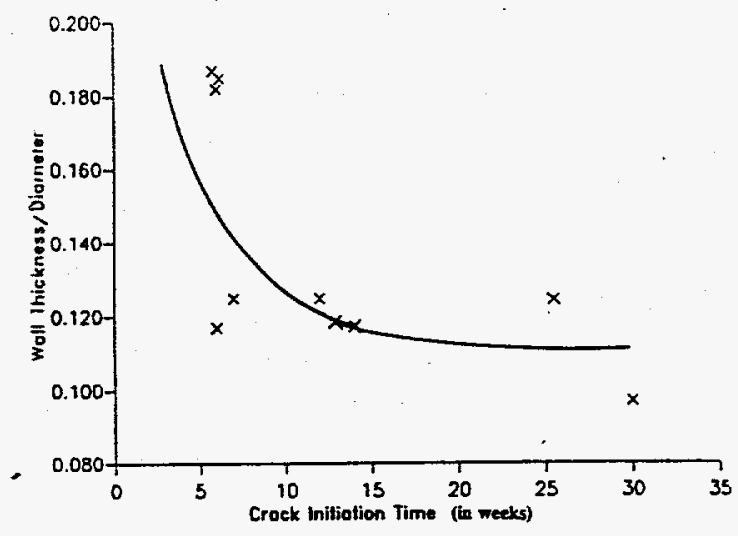

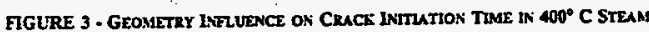


Boiling Magnesium Chloride Test

The results of testing stainless steel pipe fittings in boiling magnesium chloride solution are summarized in Table 2. Transgranular cracking was observed in elbows from all fabricators and of all sizes. Differences in crack initiation, crack depth and the extent of cracking were observed between elbow fabricators

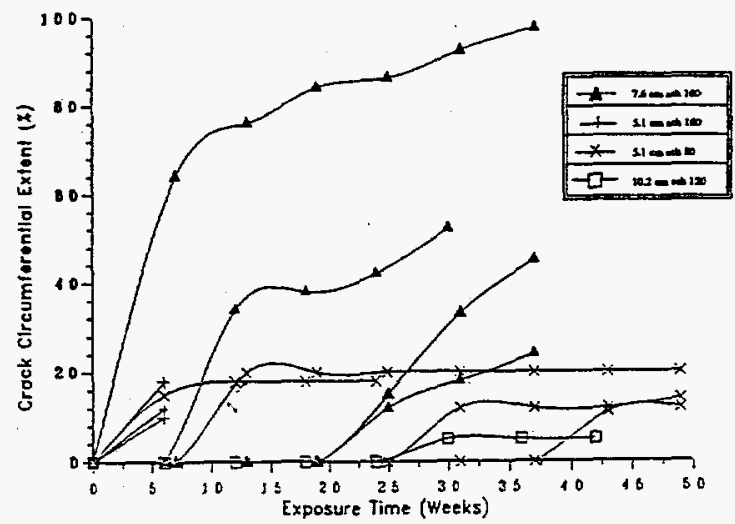

FIGURE 4 - CRACTTE EXTEAT AS A FUNCTION OF EXPOSURE TME IN $400^{\circ} \mathrm{C}$ STEAM

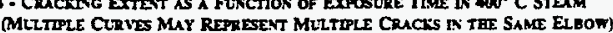
and elbow sizes.

Based on testing four $5.1 \mathrm{~cm}$ schedule 80 elbows from each fabricator for test exposures ranging from 0.5 to 22 hours, the fabricators are ranked in descending order of residual stress levels as follows: $a, b, c$ and d. Fabricator "a" elbows cracked in as early as 0.5 hours, indicative of stresses exceeding about 330-410 $\mathrm{MPa}$ (Figure 1). No cracks developed in fabricator " $b$ "-" $d$ " elbows in test times less than 2 hours, indicative of stresses less than approximately $140 \mathrm{MPa}$. The residual stress ranking of fabricators " $b "-" d "$ was based primarily on differences in the depth and extent of cracking as described in Table 2.

Testing of several different size and schedule elbows from a given fabricator demonstrated residual stress levels to generally increase as diameter decreases and wall thickness increases. This observation is based on crack depths, initiation times; and judgement of sometimes subtle differences in crack extent and appearance. Magnesium chloride testing ranked the geometry of different elbows in order of decreasing residual stress as: $5.1 \mathrm{~cm}$ schedule $160,7.6 \mathrm{~cm}$ schedule $160,5.1 \mathrm{~cm}$ schedule 80 , and $10.2 \mathrm{~cm}$ schedule 120 .

\section{Section and Layer Removal (SLR) Measurements}

SLR residual stress measurements provide a more quantitative estimate of residual stress levels than does magnesium chloride testing. Figures 5 and 6 compare the measured axial residual stresses on the intrados of $7.6 \mathrm{~cm}$ schedule 160 Alloy 600 elbows made by Fabricators "a" and "e". Axial stresses on the intrados are shown because cracking in $400^{\circ} \mathrm{C}$ steam and boiling magnesium chloride tests was predominantly circumferentially oriented and located on the elbow intrados. However, the distribution of residual stresses shown in Figures 5 and 6 is similar to the distribution at other locations measured on the elbows. The 
Fabricator "a" elbow exhibited much higher (greater than $2 \mathrm{X}$ ) tensile residual stresses than the Fabricator "e" elbow. The maximum measured residual tensile stress was $\sim 620$ $\mathrm{MPa}$ and the maximum stress on the inner surface, where SCC initiates, was $-350 \mathrm{MPa}$.

\section{DISCUSSION}

$400^{\circ} \mathrm{C}$ steam test results of Alloy 600 elbows demonstrate that SCC can occur in the absence of applied tensile stress under the sole influence of as-fabricated residual stresses. Residual stress characterization of Fabricator "a" elbows using boiling magnesium chloride testing and the SLR measurement technique confirm the presence of high (330-620 MPa) tensile residual stresses.

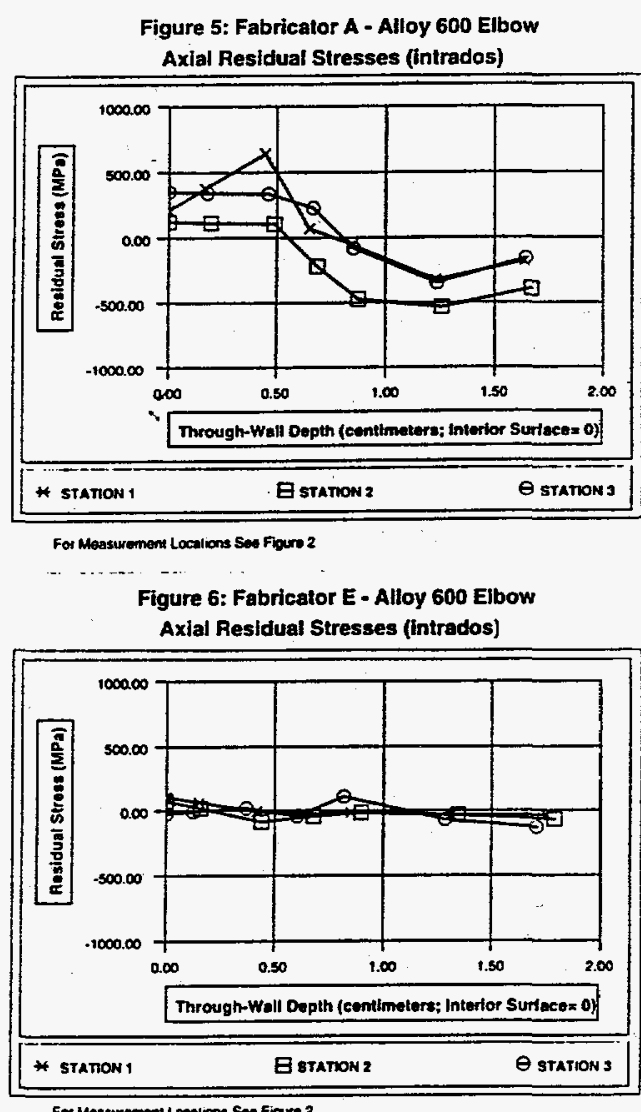

Large differences in as-fabricated residual stress levels are attributed to the differences in fabrication processes. Table 3 summarizes the fabrication processes of the elbows tested. The bending process appears to be the most influential in imparting residual stresses since the region of maximum cracking, the center of the intrados and extrados, also experiences the maximum bending stress. Fabricators "a" and " $b$ " employed the most severe bending process (cold pressed through a die) and exhibited the highest residual stresses. Somewhat higher

residual stresses

observed in

Fabricator "a"

elbows versus

Fabricator "b",

although both

employ the same

bending process, are probably due to subtle differ-

\begin{tabular}{|c|c|c|c|c|}
\hline Fabricator a & Fabricator $\mathrm{t}$ & Fabricator $\mathrm{c}$ & Fabricator d & Fabricator e \\
\hline TUBE OR BAR & TUBE OR BAR & TIBE OR BAR & TRBE OR BAR & TUBE OR BNR \\
\hline $\begin{array}{l}\text { COLD PRESSED } \\
\text { THROUGH DIE }\end{array}$ & $\begin{array}{l}\text { COLD PRESSED } \\
\text { THROUCH DEE }\end{array}$ & $\begin{array}{l}\text { HOT FORMED } \\
\text { AT SFS'C }\end{array}$ & $\begin{array}{l}\text { COLD FORMED } \\
\text { OVER HORN MOLD }\end{array}$ & $\begin{array}{l}\text { COLD FORMED } \\
\text { THROUGH DIE }\end{array}$ \\
\hline $\begin{array}{c}\text { CAUSTC CLEAN } \\
\text { NaOH) }\end{array}$ & $\begin{array}{c}\text { CAUSRC CLEAN } \\
\text { (NAOH) }\end{array}$ & $\begin{array}{l}\text { ACETONE AND } \\
\text { TRICHLORO OIEAN }\end{array}$ & ACETONE CIEAN & TRCCRLORO CLENN \\
\hline LOtO CRO MaNuTS & $1010^{\circ} \mathrm{C} 30 \mathrm{san} 7 \mathrm{TS}$ & $9000^{\circ}$ CBO ranuts & 1016 CRO Manvtrs & $2000^{\circ}$ Cros Mastrts \\
\hline WATER QUENCH & WATER QUENCH & AR COOL & WATER QUENCA & AR $\cos x$ \\
\hline $\begin{array}{l}\text { BAL SZING } \\
\text { TAPERED PLUCS }\end{array}$ & $\begin{array}{l}\text { MYDRAUUCALY } \\
\text { EXPANDING PLLES }\end{array}$ & FNAL GRINDENG & FRNAL GRNDING & $\begin{array}{l}\text { GRNDNNGI } \\
\text { TAPERED PLUGS }\end{array}$ \\
\hline
\end{tabular}
ences such as grip 
location, speed of bending, and pipe supports. The observed size/ schedule dependence provides further support for bending being the major contributor to the residual stress state. Bending thick-walled, small diameter pipe requires more bulk material deformation per volume of material than bending thin-walled, larger diameter pipe.

Other fabrication processes also appear to affect residual stresses based on the magnesium chloride test results. Fabricator "a" used ball sizing and Fabricator " $b$ " used expanding tapered plugs to meet final waterway opening tolerances. Distinctive axial strips of circumferentially oriented cracking were observed along the sidewálls of Fabricator "a" elbows and attributed to ball sizing. The presence of axial cracks near the counterbores of Fabricator "b" elbows were attributed to the use of hydraulically expanding tapered plugs. Stresses due to ball sizing and expanding plugs are judged to be lower than stresses induced by bending, because only cracks attributed to bending were present after low magnesium chloride test exposure times ( $<2$ hours).

Based on this testing, pipe fittings with lower as-fabricated residual stresses and, hence, improved SCC performance can be made by better controlling the fabrication process. Some possible controls include specifying the method and parameters for bending and specifying allowable final sizing processes.

\section{CONCLUSIONS}

1. SCC can occur in pipe fittings without applied stresses. Asfabricated tensile residual stresses can be as high as $\sim 330 \mathrm{MPa}$ on fitting surfaces.

2. Significant fabricator-to-fabricator differences exist in the asfabricated residual stresses present in pipe fittings.

3. The bending process is dominant in influencing the residual stress state, although evidence of other residual stress inducing fabrication techniques is observable.

4. Smaller fitting diameters and larger wall thicknesses lead to higher tensile residual stresses and shorter SCC initiation times.

\section{REFERENCES}

1. Denhard, E., "Effect of Composition and Heat Treatment on the Stress Corrosion Cracking of Austenitic Stainless Steel", Corrosion. Vol. 16, p.131-P40, July 1960.

\section{ACKNOWLEDGEMENT}

The authors would like to acknowledge the contributions of the following individuals, whose efforts were necessary for the successful completion of this work: A. E. Cromer, R. P. DeConno, W. C. Fichtner, K. F. LaFerriere, N. L. Perazzo, D. P. Schoonback and C. T. Woodman. 